\title{
Learning with one and two cues'
}

Rats were trained for a fixed number of trials with either two or one cues relevant and were then tested to discover how much they had learned about a single cue. When both cues were visual, Ss trained with two cues learned more about a single cue than $S$ s trained with only the single cue relevant; when one cue was visual one tactile, the two-cue group learned less about a single cue than $S_{s}$ trained with only that cue relevant. The results suggest that "analyzers" may be hierarchically arranged.

According to several recent models of discrimination learning, the more an animal learns on any one trial about a given cue the less it will learn about any other cue (e.g., Sutherland, 1964). Sutherland \& Holgate (1966) have tested and confirmed one prediction from this assumption: they found that when rats were trained with two relevant cues for a fixed number of trials, there was a negative correlation between the amount individual Ss learned about each cue. A further prediction can be made: if Ss are trained with two relevant cues for a fixed number of trials they should learn less about one of these cues than Ss trained with only that cue relevant. Babb (1957) performed an experiment on rats involving two cues-black-white and chains-no chains; three groups were trained, one with both cues relevant and one with each single cue relevant. Thirty training trials were given and Ss were then retrained on one or other of the single cues. The finding of most interest for our present purposes was that Ss trained on both cues made more mistakes in relearning the chains-no chains discrimination than Ss trained solely on that discrimination from the outset. Although this result is predicted by the present hypothesis, there is an alternative explanation for it. The Ss trained with both cues relevant were shifted from training to retraining from a situation in which black and white alleys were present to one in which only grey alleys were present, whereas those trained on chains alone from the outset experienced grey alleys throughout. The difference in the retraining scores between the two groups (which was in any case very slight, 2.6 errors against 1.2 errors to criterion) could therefore be explained as due to generalization decrementoccurring in the two-cue group, but not in the single cue groups.

In the present experiments, an attempt was made to overcome this problem by training the single cue Ss with the second cue present but irrelevant: they should suffer as much generalization decrement in tests given after training as the two-cue group.

\section{Method}

The Ss were 67 male hooded rats, about 100 days old. The apparatus was a modified Lashley jumping stand (see Sutherland \& Holgate, 1966, for a fuller description). The visual discriminanda were Perspex shapes mounted on the grey windows of the stand. Six rectangles were used-a black, white and grey horizontal, a black, white and grey vertical, each measuring $10 \times 2.5 \mathrm{~cm}$. Black and white $5 \times 5 \mathrm{~cm}$ squares were also used.

All Ss were kept on a $24 \mathrm{hr}$. feeding schedule. They were given $1.5 \mathrm{hr}$. ad lib food per day, and were run under $20 \mathrm{hr}$. hunger. They were first pretrained to jump to closed grey doors to obtain food. During training they were given 10 trials a day using a correction procedure; the side of the positive and negative stimuli was determined by Gellermann orders. After training, all Ss received transfer tests alternated with retraining trials. On retraining trials reward was only given for correct jumps, but on transfer tests $S$ was rewarded whichever side it chose.

\section{Experiment I}

Table 1 shows the experimental design. Since the two-cue experimental group and both single cue control groups were trained on black and white rectangles and tested on grey rectangles, there should be the same amount of generalization decrement due to changes in brightness for all groups. Performance on the tests should therefore reflect accurately the relative amount learned during training about the $\mathrm{V}-\mathrm{H}$ cue. All Ss were given 70 training trials. To make sure that Group $\mathrm{E}$ had learned the B-W cue, 10 further tests on the black and white squares were run after the $\mathrm{V}-\mathrm{H}$ tests with this group. There were $10 \mathrm{Ss}$ in Group E, and 11 in each of Groups $\mathrm{C} 1$ and C2.

The main results are shown in Table 2. Group E performed much better on retraining trials than did either of the single cue groups; the differences between Groups $\mathrm{E}$ and $\mathrm{C} 1$ and between Groups $\mathrm{E}$ and $\mathrm{C} 2$ are both significant by $t$ tests $(p<.001)$. Group $E$ also performed better on the orientation transfer tests than did either Group C1 or C2 $(p<.001)$.

Table 1.

\begin{tabular}{|c|c|c|c|c|}
\hline \multirow[t]{3}{*}{ Group } & \multicolumn{4}{|c|}{ Training Shapes } \\
\hline & \multicolumn{2}{|c|}{ Experiment I } & \multicolumn{2}{|c|}{ Experiment II } \\
\hline & + & - & + & - \\
\hline$E$ & $v w$ & $H B$ & $V R$ & $H M$ \\
\hline $\mathrm{Cl}$ & $\begin{array}{l}V W \\
V B\end{array}$ & $\begin{array}{l}\text { H B } \\
\text { HW }\end{array}$ & $\begin{array}{l}V R \\
V M\end{array}$ & $\begin{array}{l}H M \\
H R\end{array}$ \\
\hline $\mathrm{C} 2$ & $\begin{array}{l}V W \\
V B\end{array}$ & $\begin{array}{l}H W \\
H B\end{array}$ & $\begin{array}{l}V R \\
V M\end{array}$ & $\begin{array}{l}H R \\
H M\end{array}$ \\
\hline Tests & $V G$ & $H G$ & $\begin{array}{l}V R \\
V M\end{array}$ & $\begin{array}{l}H R \\
H M\end{array}$ \\
\hline $\begin{array}{l}V=\text { Vertical Rectangle } \\
H=H o r i z o n t a l \text { Rectangle }\end{array}$ & & $\begin{array}{l}\text { White } \\
\text { Black } \\
\text { Grey }\end{array}$ & $\begin{array}{l}R=R u b \\
M=M e t\end{array}$ & \\
\hline
\end{tabular}


Table 2 .

Percentage Correct Responses

\begin{tabular}{cccc}
\hline Experiment & Group & Retraining & Transfer \\
\hline 1 & E & 99 & $84(91)^{*}$ \\
& C1 & 66 & 57 \\
& C2 & 66 & 68 \\
11 & E & 91 & $68(75)^{+}$ \\
& C1 & 83 & 85 \\
& C2 & 82 & 80 \\
\hline
\end{tabular}

* Score on B - W tests. + Score on $R-M$ tests.

The results of the transfer tests are directly contradictory to the theoretical prediction. The Ss trained on two cues learned more about a single cue than Ss trained with only the single cue relevant. A possible explanation of this result is that analyzers are hierarchically ordered so that strengthening one visual analyzer results in strengthening other visual analyzers. To test this possibility, a second experiment was run in which the two cues used were in different modalities.

\section{Experiment II}

The design of the experiment is shown in Table 1. It was basically the same as that of Experiment I, except that a tactile cue was substituted for the brightness cue. Four plates were made to fit on top of the $\mathrm{Y}$ shaped jumping stand, so that one arm of the $\mathrm{Y}$ could be rubber and the other metal, or both arms could be rubber or both metal. Because it was impossible to find a surface midway between rubber and metal, half of the $\mathrm{V}-\mathrm{H}$ transfer trials were given with two rubber arms on the jumping platform and the remainder with two metal arms. Since Group C2 was trained with this configuration, it might be expected to show less generalization decrement than Group E, but since Group C1 was trained (like Group E) with one armalways rubber and the other always metal, it should suffer the same generalization decrement as Group $\mathrm{E}$ and any difference in transfer scores should reflect a difference in the amount learned about the $\mathrm{V}-\mathrm{H}$ cue by the two groups.

All Ss received 110 training trials. After the $\mathrm{V}-\mathrm{H}$ transfer tests, Group E Ss were given 20 transfer tests on rubber-metal with two horizontal rectangles present on half the tests and two vertical rectangles on the remaining tests. There were $12 \mathrm{Ss}$ in Groups $\mathrm{E}$ and $\mathrm{C} 1$ and 11 in $\mathrm{C} 2$.

The main results are shown in Table 2 . As would be expected the two-cue group again did better on retraining trials than either of the single-cue groups. The transfer results are, however, very different from those of Experiment I: Group C1 did significantly better in transfer tests than Group $\mathrm{E}(\mathrm{p}<.05$ by a t test, $\mathrm{p}<.02$ by a MannWhitney U test). In this experiment, therefore, the prediction from the model was confirmed.

In the transfer tests on rubber-metal Group E performed with an accuracy of $75 \%$. On the first day of initial training the same group selected rubber on $57 \%$ of trials: since they performed significantly better $(p<.001$, by a sign test) on the rubber-metal transfer tests than during their first day of training, they had clearly learned something about the rubber-metal cue. Group C1 selected rubber on $56 \%$ of trials over the first three days of training: this suggests that there may have been a small preference for rubber, but the difference from chance expectation is not significant $(p=.66$ by a sign test).

\section{Discussion}

The results of the first experiment suggest that the model adumbrated in the introduction is not adequate. These results can, however, be explained within the model if we assume that there is a hierarchy of analyzers and that strengthening of one visual analyzer strengthens others. The second experiment confirms this interpretation by showing that where the cues are sufficiently different, Ss learning two cues over a fixed number of trials learn less about one cue than do Ss learning a single cue problem. Unfortunately, we cannot be completely certain that the rubber-metal cue was serving only as a tactile cue. The difference in the results of the two experiments could be explained by supposing that Ss were learning to make muscular orienting responses. If the metal-rubber cue was learned visually, an orienting response towards the jumping platform could develop and this might prevent the development of the orienting response necessary to detect the difference between the rectangles presented on the stimulus windows. Although observations did not reveal any difference in VTE behavior between Experiment I and Experiment II, we cannot be sure that the present results are not due to Ss learning incompatible orienting responses. The results do show that under some circumstances Ss learning a two-cue problem learn less about a single cue than Ss learning only the single cue, but they do not show conclusively that this is due to an internal mechanism. Other evidence suggests that such an internal mechanism of attention is present in the rat (e.g., Sutherland \& Holgate, 1966).

It is worth adding that the notion that analyzers are hierarchically arranged would explain why overtraining on a discrimination does not necessarily retard the subsequent learning of an extra-dimensional shift problem (Tighe, Brown, Young, 1965; Sutherland, unpublished). If the present hypothesis is correct, we would expect that overtraining would retard the learning of an EDS problem only when the two cues used are detected by analyzers lying far apart in the hierarchical tree.

\section{References}

Babb, H. Transfer from a stimulus complex to differentially discriminable components. J. comp. physiol. Psychol., 1957, 50, 288-291.

Sutherland, N. S., \& Holgate, Valerie. Two-cue discrimination learning in rats. J. comp. physiol. Psychol, 1966, 61, 198-207.

Tighe, T. J., Brown, Paul L., \& Young, Edward A. The effect of overtraining on the shift behaviour of albino rats. Psychon. Sci., $1965,2,141-142$

\section{Note}

1. This work is part of a project on "Stimulus Analyzing Mechanisms" supported by the American Office of Naval Research (Contract N62558-4791). We are grateful to Susan Stellar for help in the conduct of the experiments and to $\mathrm{E}$. P. Lovejoy for valuable comments. 